\title{
Conductive Cotton Textile from Safely Functionalized Carbon Nanotubes
}

\author{
Mohammad Jellur Rahman' ${ }^{1}$ and Tetsu Mieno ${ }^{1,2}$ \\ ${ }^{1}$ Graduate School of Science \& Technology, Shizuoka University, Shizuoka 422-8529, Japan \\ ${ }^{2}$ Department of Physics, Shizuoka University, Shizuoka 422-8529, Japan \\ Correspondence should be addressed to Tetsu Mieno; sptmien@ipc.shizuoka.ac.jp
}

Received 23 January 2015; Accepted 22 April 2015

Academic Editor: Theodorian Borca-Tasciuc

Copyright (C) 2015 M. J. Rahman and T. Mieno. This is an open access article distributed under the Creative Commons Attribution License, which permits unrestricted use, distribution, and reproduction in any medium, provided the original work is properly cited.

\begin{abstract}
Electroconductive cotton textile has been prepared by a simple dipping-drying coating technique using safely functionalized multiwalled carbon nanotubes ( $f$-MWCNTs). Owing to the surface functional groups, the $f$-MWCNTs become strongly attached with the cotton fibers forming network armors on their surfaces. As a result, the textile exhibits enhanced electrical properties with improved thermal conductivity and therefore is demonstrated as a flexible electrothermal heating element. The fabricated $f$-MWCNTs/cotton textile can be heated uniformly from room temperature to $c a .100^{\circ} \mathrm{C}$ within few minutes depending on the applied voltage. The textile shows good thermal stability and repeatability during a long-term heating test.
\end{abstract}

\section{Introduction}

Carbon nanotubes (CNTs) are very important materials having very high aspect ratio with unique electrical and thermal properties. For these reasons, they are used in coating technologies for the preparation of lightweight and flexible electrothermal materials and have been used in the advanced technologies particularly for the aviation and aerospace industries, microreactor technologies, and different kinetic systems [1-8]. Resistive wires made of metal alloys have been used as the heat source in many appliances, but in those cases flexibility is poor and heat is localized at the wire [8]. If cotton textile can be used as a heating element it would offer a spectrum of advantages over the traditional materials $[1,8-10]$. However, the main drawbacks of the cotton fibers are their low thermal and electrical conductivities and high flammability [11-13].

Cotton fibers are highly moisture absorptive and can absorb large amount of water or other polar solvents $[1$, $7,10]$. Therefore, utilizing the coating method large-scale conductive cotton manufacturing process has already been demonstrated and reported as diverse smart textiles [5-7, 11, 14-16]. CNTs have been reported as excellent conductive coating materials for different applications [9, 10, 17-22]. To fully utilize the functions and properties of the CNTs, they are dispersed into different solvents using either surfactant or harsh oxidative treatment, which are not environmentally safe and degrade the properties of the CNTs.

In this study, we have used safely functionalized multiwalled CNTs ( $f$-MWCNTs) in producing conductive cotton textiles using a simple dipping-drying coating method. To functionalize the MWCNTs a citric-acid-assisted plasma functionalization process is used, which is less destructive to the CNT structure [23]. The oxygen-containing surface groups on the $f$-MWCNTs enable them to stably disperse in water to produce MWCNT ink, which subsequently are incorporated in the cotton textile by repeatedly dipping the textile into it. The $f$-MWCNT coated cotton $(f$ MWCNTs/cotton) textile exhibits enhanced electrical conductivity and improved thermal stability. Therefore, the textile is proposed to be used as light-weight and flexible electrothermal heating element in everyday clothing, which can efficiently heat up surfaces of any size and shape featuring a rapid thermal response. The textile could open new avenues in designing more comfortable consumer products and new types of user interaction concepts. 


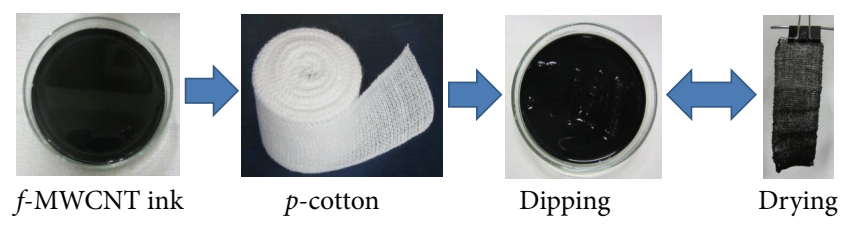

Figure 1: Coating scheme of the $f$-MWCNTs/cotton textile.

\section{Experimental}

2.1. Functionalization of the MWCNTs. To increase the dispersibility in water, pristine MWCNTs ( $p$-MWCNTs: SigmaAldrich, outer diameter $=10-30 \mathrm{~nm}$, inner diameter $=3-$ $10 \mathrm{~nm}$, length $=1-10 \mu \mathrm{m}$, purity $>90 \%$ ) are effectively functionalized by the citric-acid-assisted RF oxygen plasma treatment method developed in our laboratory [23]. For this, $p$-MWCNTs are sonicated in pure ethanol, dried, and subsequently soaked in citric acid solution, and RF $(13.56 \mathrm{MHz})$ oxygen plasma is carried out under optimum conditions. After the plasma treatment, a large number of carboxyl groups are observed to be attached onto the surfaces of the MWCNTs.

2.2. Sample Preparation. A piece of $100 \%$ cotton ( $p$-cotton) textile of $c a .24 \mathrm{mesh} /$ inch with thread diameter of $c a$. $0.25 \mathrm{~mm}$ is dipped into the $0.25-1.0 \mathrm{wt} \%$ dispersed solution of $f$-MWCNTs in water and dried in air at room temperature. Steps of the $f$-MWCNT loading process in the cotton textile are shown in Figure 1. The textile sheet is dipped and dried repeatedly until the electrical resistance for an area of $5 \times$ $5 \mathrm{~cm}^{2}$ becomes of the order of several $\mathrm{k} \Omega$. To calculate the amount of the loaded $f$-MWCNTs $\left(W_{\mathrm{nt}}\right)$, the cotton textile is weighed before dipping in the $f$-MWCNT ink and after drying it sufficiently.

2.3. Characterization. Electrical resistance, $R=V / I$, of the textile is obtained from the current, $I$, in the circuit, and potential drop, $V$, across the sample measured by a digital multimeter (Iwatsu VOAC 87, Japan). A dc voltage, $V_{\text {in }}$, is applied by a regulated power supply (Kikusui Electronics PAB 350-0.2, Japan) between two Nickel electrodes (thickness of $0.15 \mathrm{~mm}, 40 \mathrm{mesh}$, Nilaco Co., Japan) of width $D$ placed on the coated cotton textile at a distance $L$. The sheet resistance $\left(R_{s}\right)$ of the textile is then calculated using this formula: $R_{s}=R \times(D / L)$. MWCNT coating uniformity on the cotton fibers is confirmed by the scanning electron microscope (SEM) images taken by a JEOL JSM 6510LV SEM at an operating voltage of $20 \mathrm{kV}$. Thermal stability is observed by a thermogravimetric analyzer (TG/DTA: Rigaku Thermo Plus TG 8120). The temperature of the $f$-MWCNTs/cotton textile is measured using a thermometer (AS ONE TM-301) and an infrared camera (FLIR i3, emissivity $=0.95$, focal length $=$ $6.8 \mathrm{~mm}$ ). A standard washing test (ISO 105 C06-1994) is performed on the coated textile using a standard launder meter (LM 8D type, SUGA Test Instrument) to study the toughness of the $f$-MWCNTs on the cotton fiber.

\section{Results and Discussion}

The enhancement of dispersion stability is confirmed from visual observation of the mixer of MWCNTs in pure water and measuring the settling speed for a dispersion using the absorbance data of the UV-visible spectroscopy as shown in Figures 2(a) and 2(b), respectively [23]. Attachment of the functional groups onto the MWCNTs is studied by a Fourier transform infrared (FT-IR) spectrometer (Shimadzu Co., 8700, 100 scans averaged). The FT-IR spectra of the $p$ MWCNTs and $f$-MWCNTs are presented in Figure 2 after the base line correction. The $f$-MWCNT spectrum shows additional peak compared to that of the $p$-MWCNTs at ca. $1713 \mathrm{~cm}^{-1}$, which corresponds to the $\mathrm{C}=\mathrm{O}$ stretching bonds and the broad band at $c a .3200 \mathrm{~cm}^{-1}$ corresponding to the $\mathrm{O}-\mathrm{H} /-\mathrm{OH}$ bonds [23]. Therefore, carboxyl groups are considered to be attached on the MWCNTs after functionalization.

The improved dispersion of the $f$-MWCNTs is further confirmed from the transmission electron microscope (TEM) (HITACHI High Technology Co., H-7500, acceleration voltage of $100 \mathrm{kV}$ ) images as shown in Figure 3. Compared to the $p$-MWCNTs, the dispersibility of the $f$-MWCNTs is enhanced clearly as shown in Figures 3(a) and 3(b). In the higher magnification images, it is observed that the structural quality of the MWCNTs remains similar after the citric-acidassisted RF plasma functionalization, which is also confirmed from the Raman spectroscopy as described in [23].

3.1. Improved Electrical Properties. When the p-cotton textile is dipped into the $f$-MWCNT ink it becomes easily coated with the $f$-MWCNTs. After sufficient amount of loading ( $>5.0 \mathrm{wt} \%$ ), the coated textile shows measurable resistance, $R$. The schematic setup of the resistance measurement is shown in Figure 4(a). This is owing to the formation of conducting path on the cotton fibers. $R$ values of the coated textile are observed to vary linearly with $L$ as shown in Figure 4(b). As $W_{\text {nt }}$ increases with the dipping-drying cycles, $R_{s}$ of the $f$-MWCNTs/cotton textile decreases gradually as shown in Figure $4(\mathrm{c})$. The $f$-MWCNTs/cotton textile becomes conductive with $R_{s} c a .9 .65 \mathrm{k} \Omega / \mathrm{sq}$, when $W_{\mathrm{nt}}$ is $c a .18 .5 \mathrm{wt} \%$. After 1st and 2nd dipping cycles, only parts of the textile become poorly conductive. However, after 5 6 cycles of dipping, the variation of $R_{s}$ along the width or length becomes very small indicating the homogenous coating of the cotton textile. Comparing the $R_{s}$ of the $f$-MWCNTs/cotton textiles ( $c a$. $10^{2} \mathrm{k} \Omega / \mathrm{sq}$ ) with those of the $p$-MWCNTs/cotton textiles ( $c a$. $10^{5} \mathrm{k} \Omega / \mathrm{sq}$ ) for the same $W_{\mathrm{nt}}$, it is realized that homogenous dispersion of the MWCNTs is very important in the coating process. When thickness of the $f$-MWCNTs/cotton textile is, $b \approx 0.5 \mathrm{~mm}$, the bulk resistivity, $\rho=[R(D \times b)] / L$, is calculated to be ca. $2.3 \mathrm{k} \Omega \cdot \mathrm{m}$, and the conductivity, $\sigma=1 / \rho$, is ca. $0.43 \mathrm{~S} / \mathrm{m}$. The $I-V_{\text {in }}$ characteristic curve, as presented in Figure 4(d), shows Ohmic conduction in the textile.

Optical microscope (Olympus BX 60) and SEM images of the $p$-cotton, $p$-MWCNTs/cotton, and $f$-MWCNTs/cotton textiles at different magnifications are presented in Figure 5. It is observed that the $p$-MWCNTs become roughly coated 


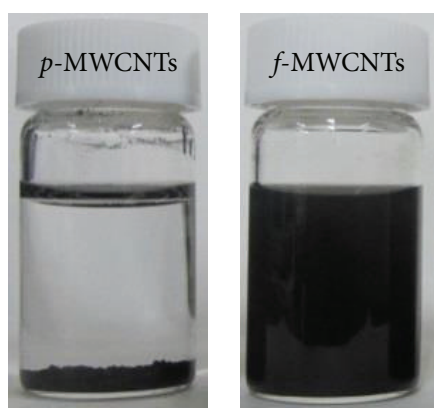

(a)

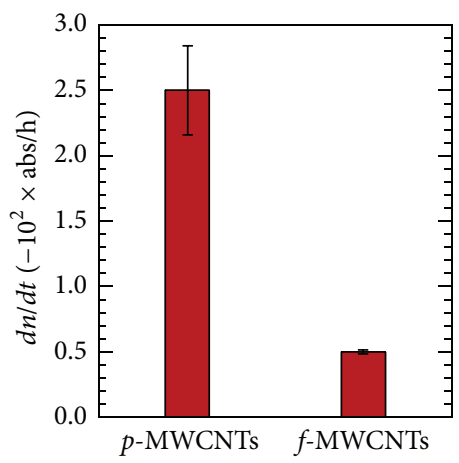

(b)

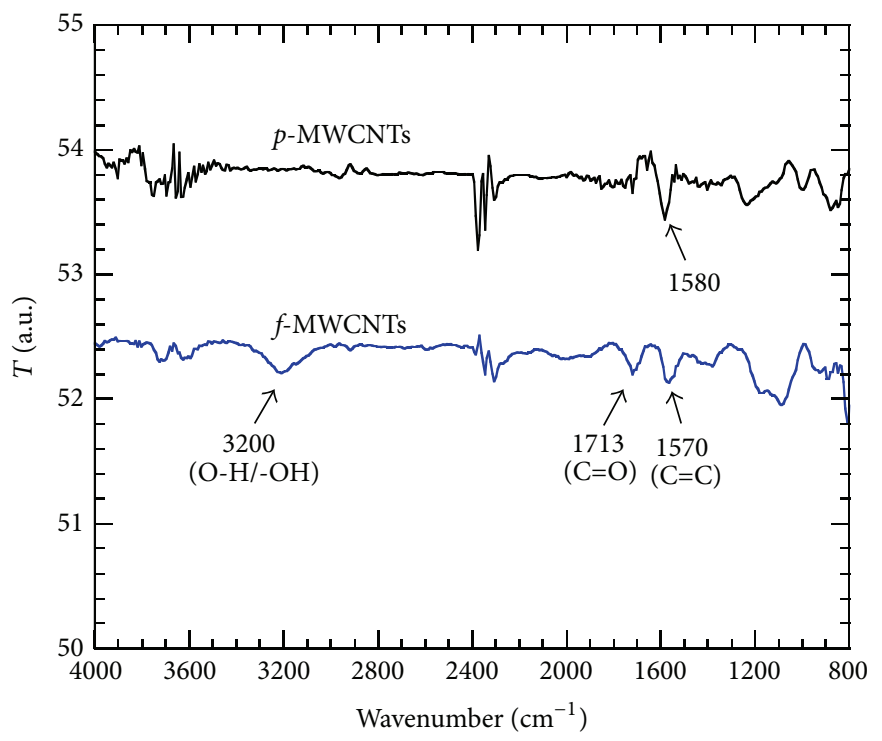

(c)

FIGURE 2: (a) Photograph of the dispersion of the $p$-MWCNTs and $f$-MWCNTs taken after 20 days and (b) the settling speed measured from the UV-Vis spectroscopy. (c) FT-IR spectra of the $p$-MWCNTs and $f$-MWCNTs.

on the cotton fibers, because they become coagulated in the solvent and make cluster of islands on the fibers instead of coating them uniformly. But, the $f$-MWCNTs coat the cotton fibers uniformly and are firmly attached to them as shown in the cross-sectional view of the fiber in Figure 5(n). Cotton has hydroxyl groups in the cellulose fibers $[1,10,16]$, which enable the $f$-MWCNTs to form strong hydrogen bonds with the surfaces of the fibers, resulting in the high density network coating $[1,24,25]$.

After dipping in the $f$-MWCNT ink the $p$-cotton textile becomes black as shown in Figure 6(a), which is owing to the formation of MWCNT network armor on each cotton fiber as shown schematically in Figure 6(b). After 10 cycles of dipping in $0.5 \mathrm{wt} \% f$-MWCNT ink, the resulting $f$-MWCNTs/cotton textile becomes conductive with $\sigma$ more than $c a .0 .20 \mathrm{~S} / \mathrm{m}$. As a demonstration of the conductivity, an LED device connected to a dc source can be easily powered through the prepared conducting textile as shown in Figure 6(c). For sufficient brightness of the LED, it is observed that input voltage of $c a .18 \mathrm{~V}$ is needed for the textile of length $5.0 \mathrm{~cm}$, where the current is $c a .2 .85 \mathrm{~mA}$.

It is observed that when $p$-MWCNT coated textile is dipped into clean water a lot of MWCNTs get detached from the textile and precipitated in the water. As a result, the bare parts of the cotton fiber increase whereas the $f$-MWCNTs cannot be removed from the $f$-MWCNT coated textile after normal washing, and the $f$-MWCNTs/cotton textile remains as black as it is just coated. To measure the detached amount of MWCNTs quantitatively more investigation is necessary. To study the toughness of the $f$-MWCNTs on the cotton fiber, a piece of $f$-MWCNTs/cotton textile is washed in a standard launder meter with detergent/DI water $(0.5 \mathrm{~g} / \mathrm{L})$ at a temperature of $40 \pm 2^{\circ} \mathrm{C}$ with a revolution rate of $0.67 \mathrm{~Hz}$ for $30 \mathrm{~min}$. It is observed that only a very little portion of the loaded $f$-MWCNTs are removed from the textile and lots of MWCNTs still remain on the fiber as shown in Figures $6(\mathrm{~d})$ and 6(e), suggesting the high level of toughness of the $f$-MWCNTs on the textile. 


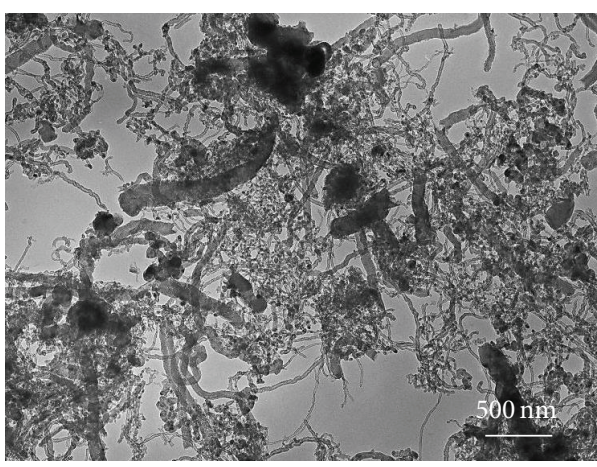

(a)

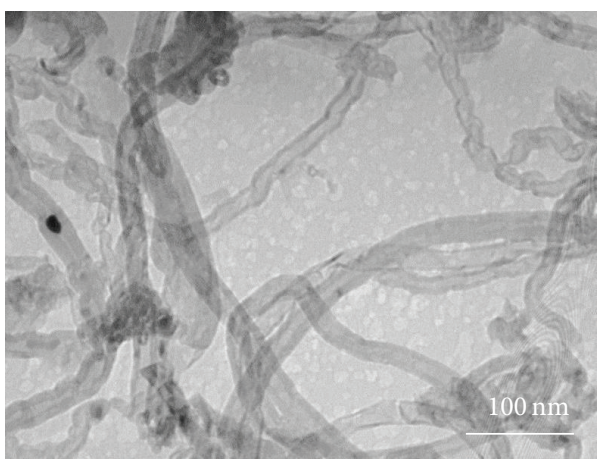

(c)

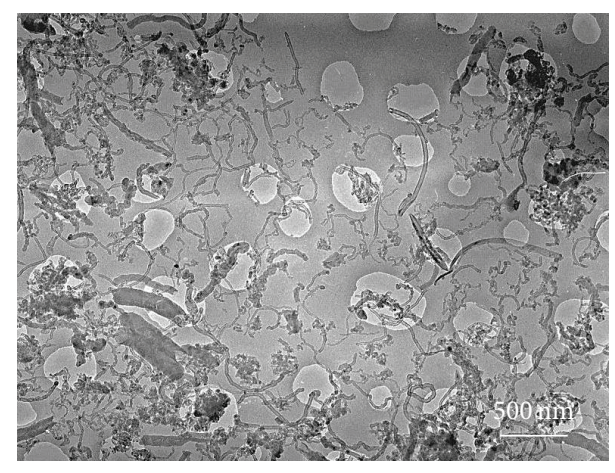

(b)

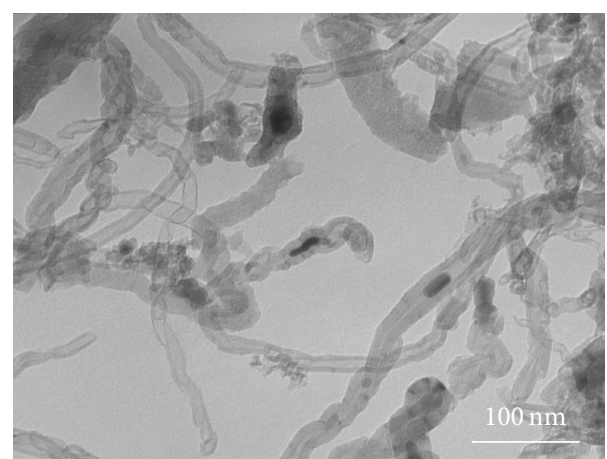

(d)

FIgURE 3: TEM images of the (a and c) p-MWCNTs and (b and d) $f$-MWCNTs in two different magnifications.

3.2. Improved Thermal Properties. Thermal conductivity, $k$, for the textile is measured using the conventional "Lees' Disc" method. It is observed that $k$ of the $p$-cotton textile is $c a$. $0.027 \mathrm{~W} / \mathrm{mK}$, which is close to the literature values [10] and that of the $f$-MWCNTs/cotton textile is $c a .0 .045 \mathrm{~W} / \mathrm{mK}$, which suggests $\mathrm{ca}$. 70\% improvement. It is conjectured that strong bonding between the $f$-MWCNTs and the cotton fibers ensure better heat transfer in the textile [10, 25].

From the TG-DTA curves for the $p$-cotton, $p$-MWCNTs/ cotton, and $f$-MWCNTs/cotton textiles taken under air ambient at a heating rate of $10^{\circ} \mathrm{C} / \mathrm{min}$ as shown in Figure 7 , it is observed that the thermal degradation of the cotton fibers mainly occurs in two different steps. Below $300^{\circ} \mathrm{C}$, there is only a small weight loss, which is attributed to the release of the physically adsorbed water [26]. The first exothermic peak is observed between 300 and $400^{\circ} \mathrm{C}$, which corresponds to the dehydration and decarboxylation reactions of the cellulose [27]. The second step occurs between 400 and $550^{\circ} \mathrm{C}$ that can be attributed to the oxidative degradation of the char formed in the first step. The $f$-MWCNTs/cotton textile shows ca. $10 \%$ less combustion after the first step and the final combustion is delayed by $\mathrm{ca} .100^{\circ} \mathrm{C}$. This signifies that the thermal stability of the textile is improved compared to the $p$-cotton or $p$-MWCNTs/cotton textiles. This improvement in thermal stability is due to the uniform coating of the cotton fibers by the $f$-MWCNTs, because thermal stable MWCNTs act as armor for the cotton fibers protecting them from burning in a relatively lower temperature. The additional DTA peaks for the $f$-MWCNTs/cotton textile at $c a .407$ and ca. $495^{\circ} \mathrm{C}$ may correspond to the combustion of the hydrogen bonds between the groups on the fiber and $f$-MWCNTs. This study contributes to better understanding of the thermal degradation of the $p$-cotton and $f$-MWCNT coated cotton fibers, which may aid to develop ways to improve the thermal stability and flaming characteristics of the cotton fibers as relevant for future applications [11].

The combustion processes of the $p$-cotton and $f$ MWCNTs/cotton textiles are studied by hanging them on a metal supporter and then igniting simultaneously by a gas flame. It is observed that the $p$-cotton textile catches fire immediately and burns quickly to ashes completely. However, the $f$-MWCNTs/cotton textile becomes charred only, which provides direct evidence of improved flame retardancy.

3.3. The Textile as a Low Powered Flexible Heater. The above results strongly suggest that the $f$-MWCNTs/cotton textile can be used as an electrothermal heating element. The electric heating behavior of the patterned textiles is evaluated by measuring the changes in the resistance and temperature under $V_{\text {in }}=10-60 \mathrm{~V}$. When few layers of such $f$-MWCNTs/cotton textiles $\left(5 \times 5 \mathrm{~cm}^{2}\right)$ are stacked together, the resultant $R$ values become low enough to produce heat applying small voltages based on the Joule heating from electric power $[18,28]$. The $f$-MWCNTs/cotton textile shown in Figure 8(a) is folded in four layers to obtain $R_{s} c a .1 .67 \mathrm{k} \Omega / \mathrm{sq}$. When $V_{\text {in }}$ is applied as shown schematically in Figure $8(\mathrm{~b})$, it is observed that heat starts to radiate from the textile indicating the increase in temperature with time as presented in Figures 8(c) and 8(d). 


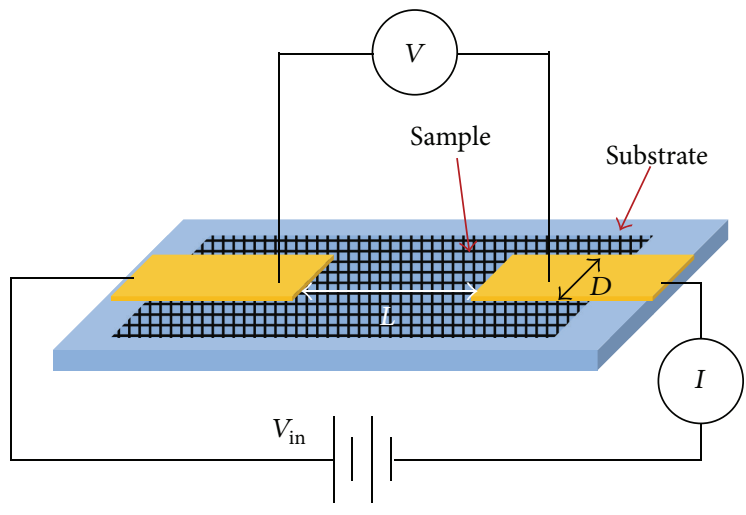

(a)

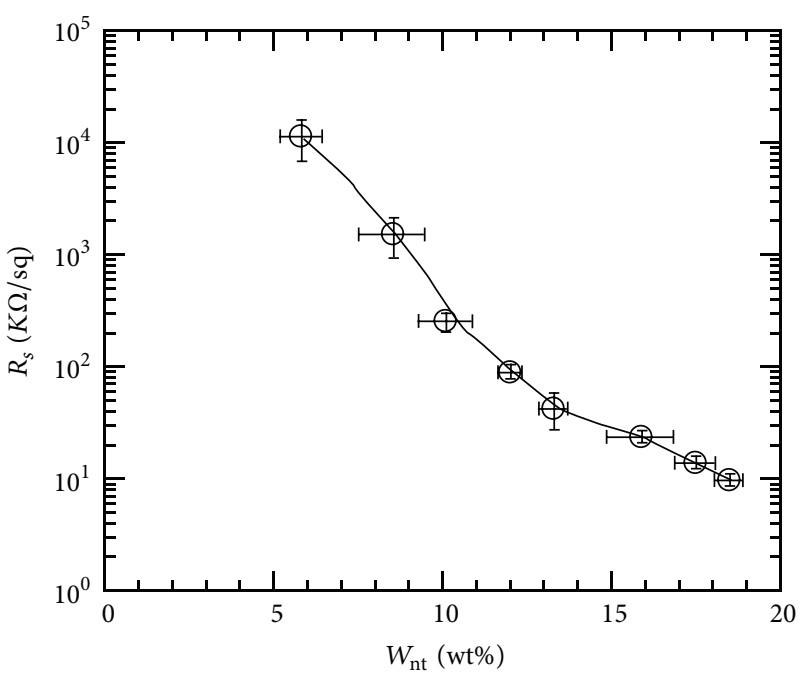

(c)

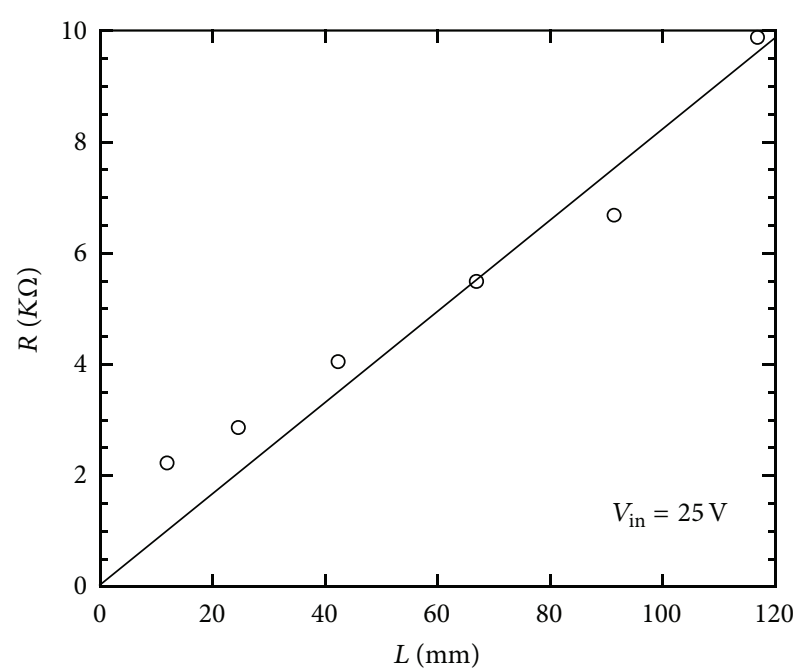

(b)

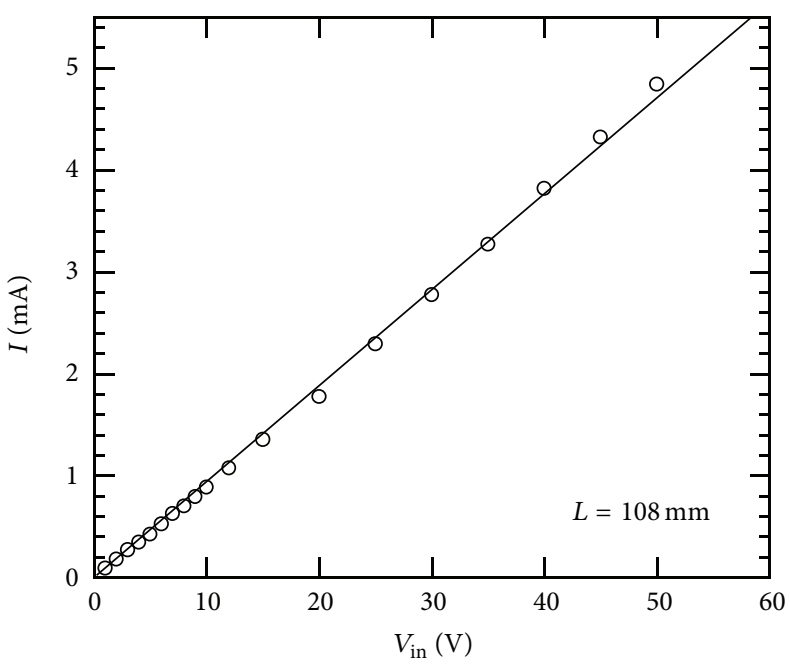

(d)

Figure 4: (a) Schematic setup of the sheet resistance $\left(R_{s}\right)$ measurement. (b) Variation of $R$ across the $f$-MWCNTs/cotton textile versus the distance between the electrodes, $L$. (c) The $R_{s}$ versus the loaded $f$-MWCNTs, $W_{\text {nt }}$, in the cotton textile. (d) $I$ - $V_{\text {in }}$ curve for $L=108$ mm showing the linear conduction.

The little difference between the thermocouple-based and infrared-based measurements, also shown in Figure 8(e), validates the data obtained from the measurement, which is because of the slow response of the thermocouple owing to the slow heat propagation [20]. Temperature of the $f$ MWCNTs/cotton textile can be increased above $70^{\circ} \mathrm{C}$ within 5 min depending on the applied voltage.

When an electric power of approximately $0.1 \mathrm{~W} / \mathrm{cm}^{2}$ is applied to the textile its temperature increases uniformly to ca. $84^{\circ} \mathrm{C}$, which is shown in the IR image of Figure $8(\mathrm{e})$. The white color indicates the area over which the temperature reaches more than $90 \%$ of the maximum temperature. Temperature homogeneity of this textile as heating element is better than those made with only stainless steel yarns, because in the latter case heat is produced and localized only at the conductive yarns $[9,21]$. Uniform distribution and dissipation of heat allow the heating element to be located in close proximity to the heated area in order to maximize warmth/heat production/output, to minimize response time, and to eliminate hot spots. The samples with 4 layers show a temperature increase of $c a .40^{\circ} \mathrm{C}\left(\mathrm{ca} .0 .1 \mathrm{~W} / \mathrm{cm}^{2}\right)$ within $0.5 \mathrm{~min}$. The heat releasing ability is also high for the coated textile, which is observed from the exponential decrease of the temperature to the room temperature within few minutes. The temperature of the water could be raised to more than $80^{\circ} \mathrm{C}$ inserting the textile heater into it.

The flexibility of the textile as heating element is studied by measuring the changes in the temperatures within 20 cycles of bending over a time frame of $80 \mathrm{~min}$. It is observed that with repeated bending, the current conducting through the heating textile does not change significantly and the decrease in temperature is very small as shown in Figure 8(f). 


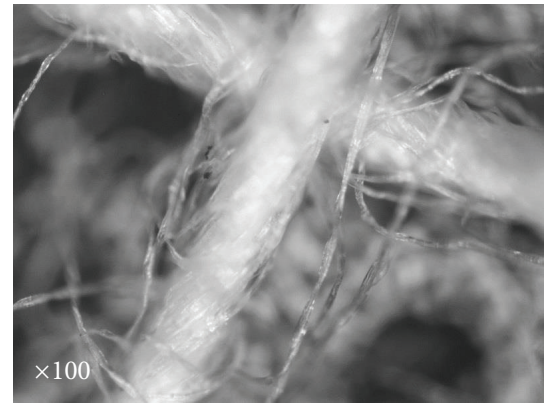

(a)

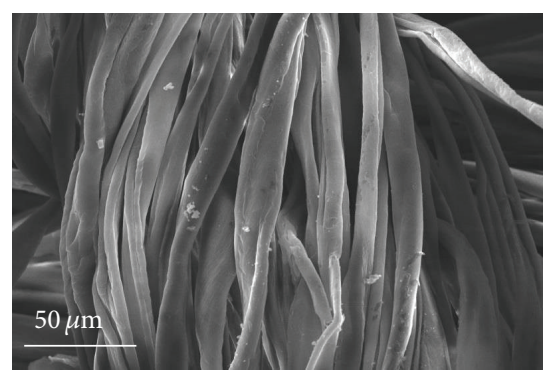

(d)

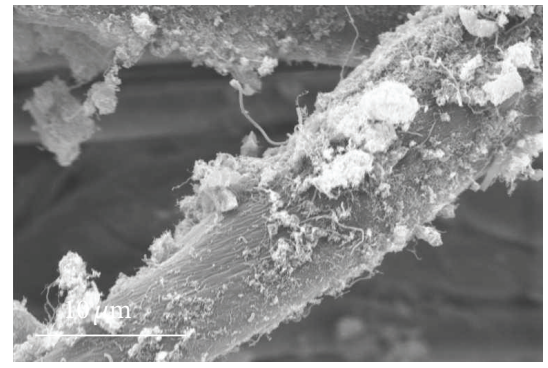

(g)

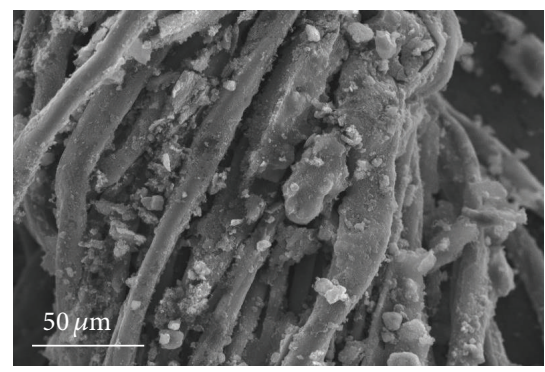

(j)

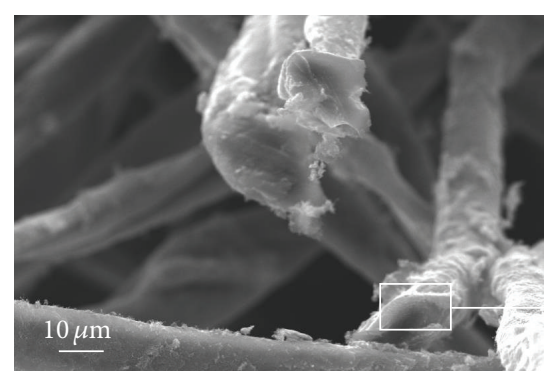

$(\mathrm{m})$

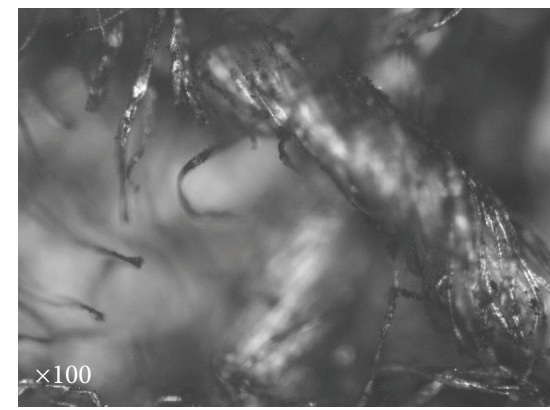

(b)

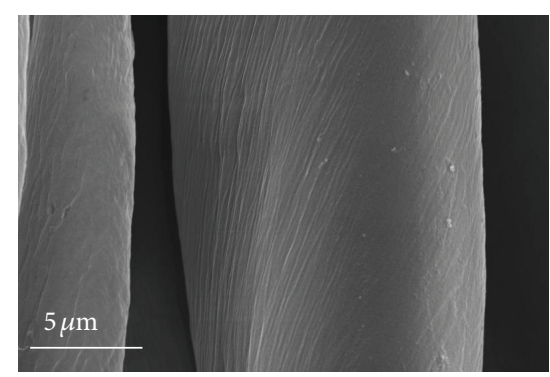

(e)

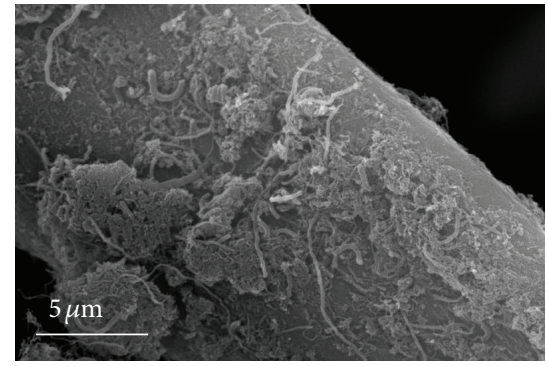

(h)

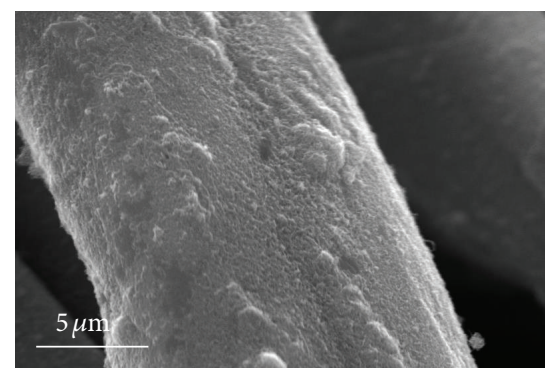

(k)

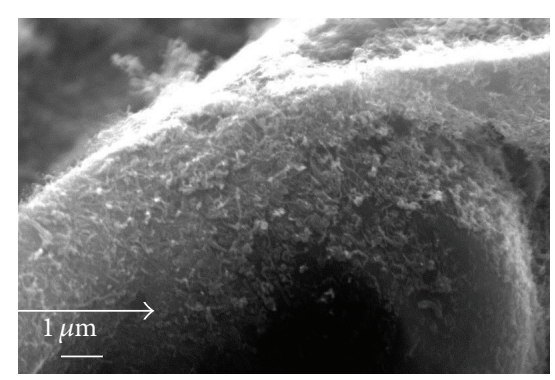

(n)

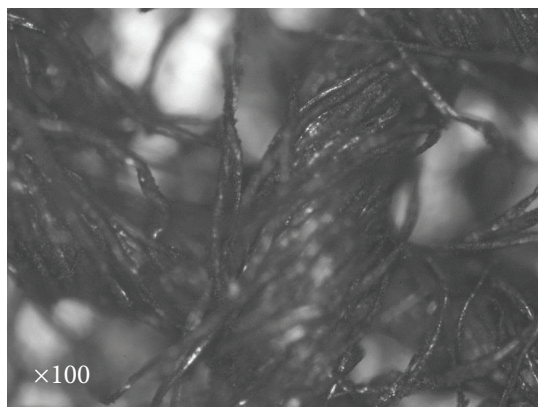

(c)

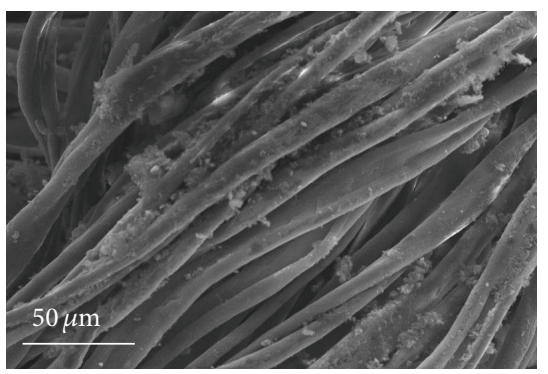

(f)

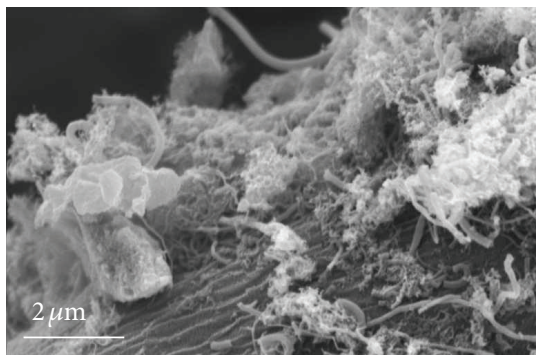

(i)

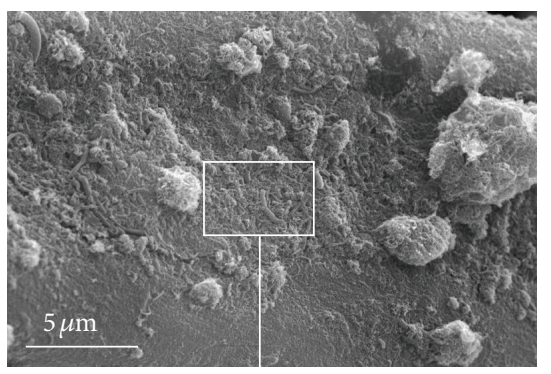

(l)

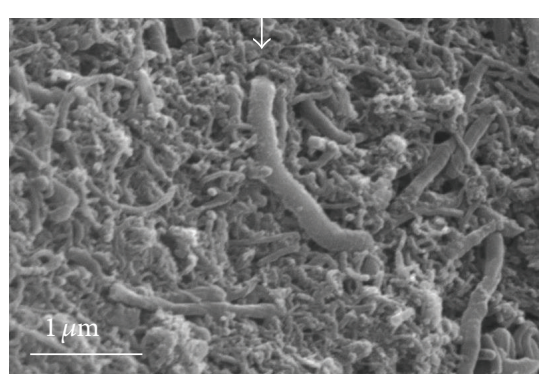

(o)

Figure 5: (a-c) Optical microscope images and (d-o) SEM images of the (a, d, and e) p-cotton, (b and f-i) p-MWCNTs/cotton, and (c and j-o) $f$-MWCNTs/cotton textile fibers at different magnifications. 


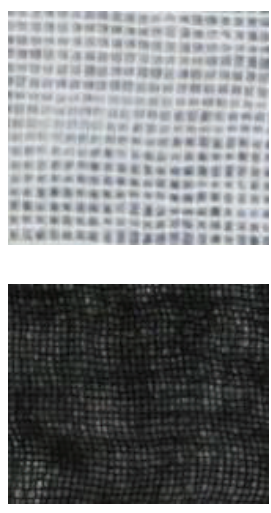

(a)

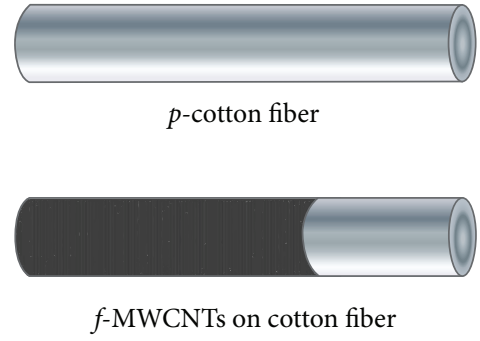

(b)

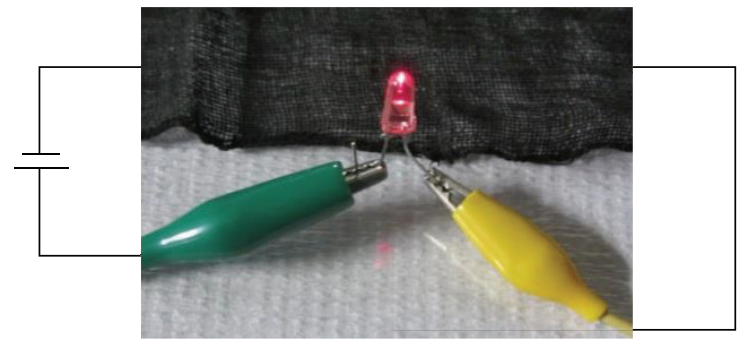

(c)

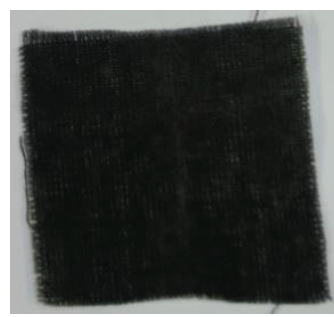

(d)

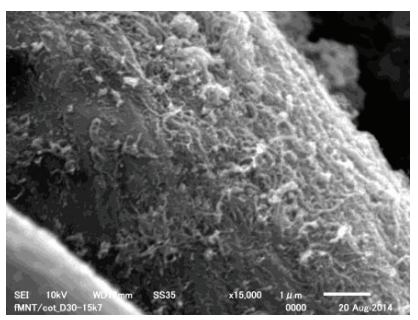

(e)

Figure 6: (a) Comparison between the $p$-cotton (upper) and $f$-MWCNTs/cotton (lower) textiles. (b) Schematic of the fiber coating. (c) The $f$-MWCNTs/cotton textile acting as a conducting path in the emission of an LED. (d) The textile after a standard washing test for 30 min. (e) SEM image of the cotton fiber after the washing test.

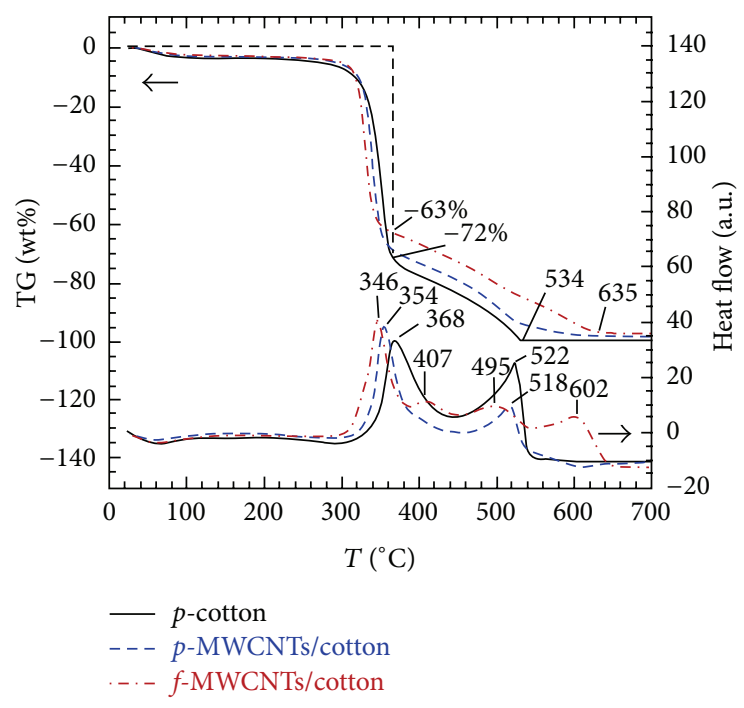

FIGURE 7: TG-DTA curves for the $p$-cotton, $p$-MWCNTs/cotton, and $f$-MWCNTs/cotton textiles.

These indicate that the flexibility of the textile is high, which along with the temperature homogeneity suggests the use of the $f$-MWCNTs/cotton textile as a flexible heating element. These lightweight textiles can be configured and cut into any size or any shape and are useful for portable heating system. For heating up to $\mathrm{ca} .90^{\circ} \mathrm{C}$, a power of $0.1 \mathrm{~W} / \mathrm{cm}^{2}$ is required, which is much lower than that of the conventional wired heater $\left(c a .0 .3 \mathrm{~W} / \mathrm{cm}^{2}\right)$ [29]. This allows more efficient heating with less energy, which will find potential applications in garments and in transportation to improve thermal comfort.

It was informed that CNTs have toxic effects. Isolated CNTs in human body would make damage to the organic cells. In order to avoid these effects, the textile can be covered with some additional fabric or by other means before using it in different applications, by which direct contact to the human body or diffusion into the air could be avoided.

\section{Conclusions}

Nonconducting cotton textile becomes electroconductive by repeatedly dipping into the stable dispersion of $f$-MWCNT in water and drying in air. The $f$-MWCNTs uniformly and strongly cover the individual cotton fibers, which remain attached even after $30 \mathrm{~min}$ of standard washing. After several cycles of dipping into $f$-MWCNT ink the textile becomes conductive enough to be used as wire in lighting up an LED, and its conductivity becomes more than $0.20 \mathrm{~S} / \mathrm{m}$ depending on the loaded content of $f$-MWCNTs in it. The thermal conductivity of the textile is enhanced by ca. 70\%, and the thermal stability and flame retardancy are also improved. As a demonstration of practical use, the textile is shown as a conductive textile heater designed with parallel electrodes. The temperature of the $f$-MWCNTs/cotton textile can be increased homogeneously to $\mathrm{ca} .80^{\circ} \mathrm{C}$ within $\mathrm{ca} .5 \mathrm{~min}$ by applying an electric power of $c a .0 .1 \mathrm{~W} / \mathrm{cm}^{2}$, which is much 


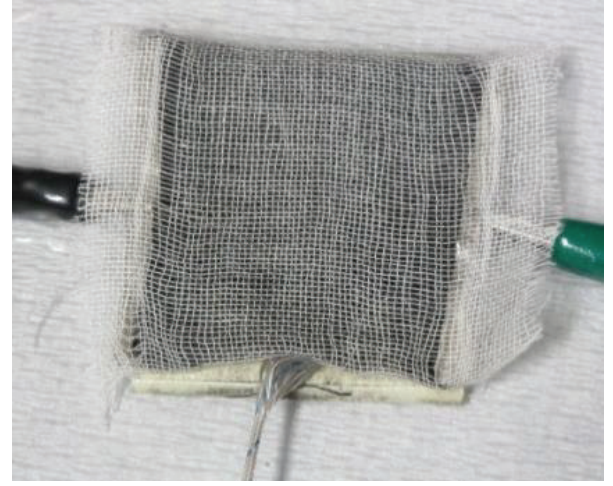

(a)

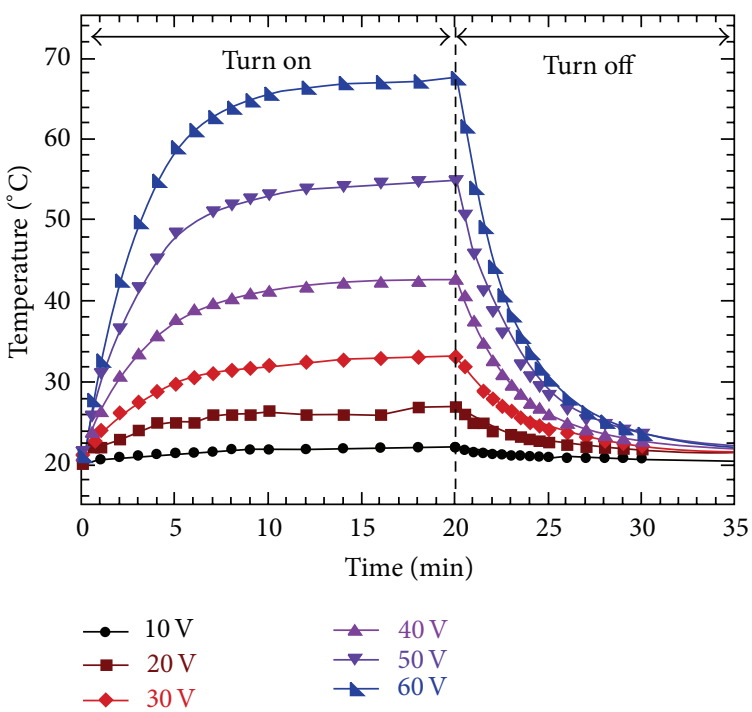

(c)

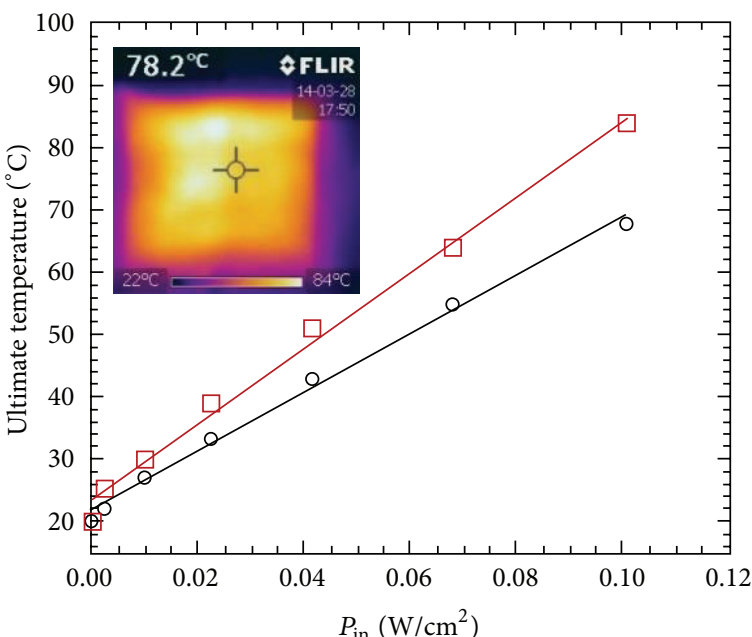

- - Thermocouple

$\square$ FLIR camera

(e)

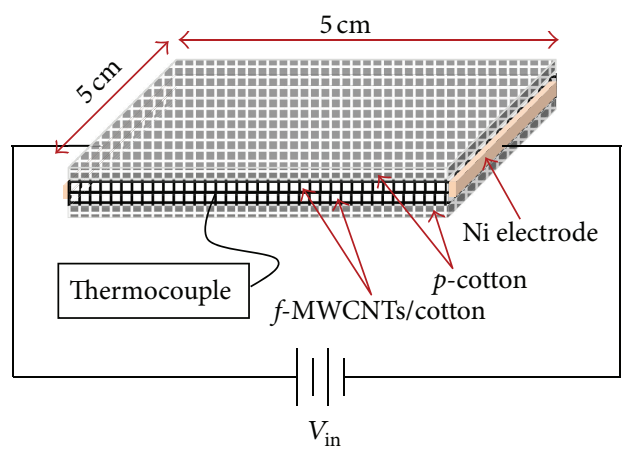

(b)

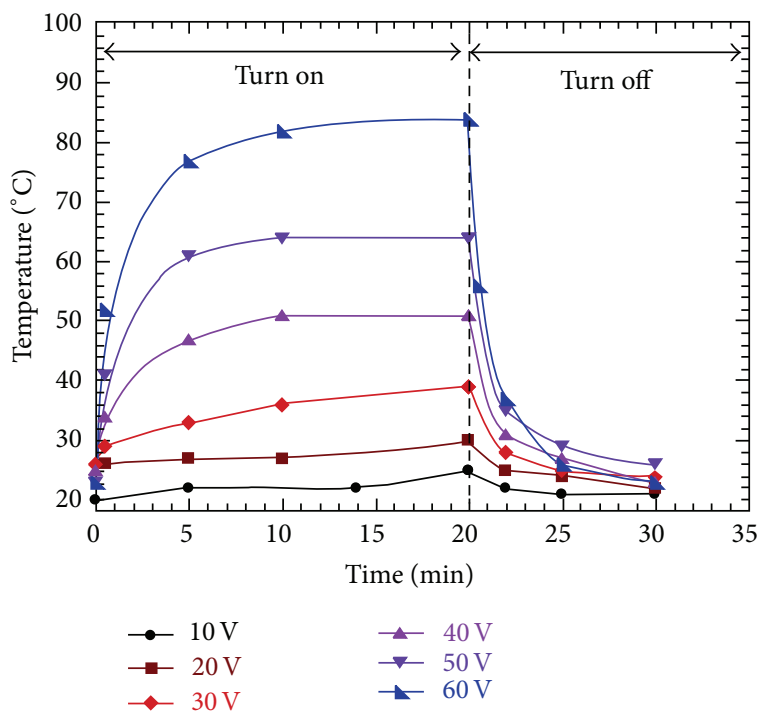

(d)

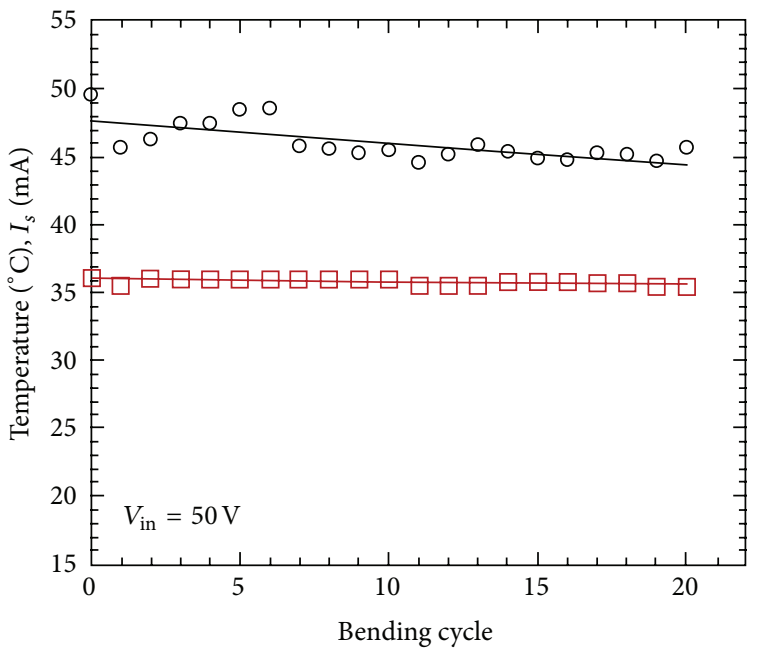

- Temperature

$\square$ Current, $I_{S}$

Figure 8: Heating and cooling temperatures of the $f$-MWCNTs/cotton textile of $R_{s}=1.67 \mathrm{k} \Omega / \mathrm{sq}$ using a dc power supply. (a) The $f$ MWCNTs/cotton textile covered with one layer of $p$-cotton sheet. (b) Schematic of the heat measurement setup. Heating and cooling temperatures at the center of the textile with time measured (c) by a thermocouple and (d) by an IR camera. (e) The increase in ultimate temperature of the $f$-MWCNTs/cotton textile with input power (inset: thermal image at $V_{\text {in }}=60 \mathrm{~V}$ showing the uniform heating of the textile). (f) Changes in the temperature and current after repeated bending. 
less than the power required for conventional wired heater. In our process the dispersion of the MWCNTs is achieved by functionalizing them with a safe and surfactant-free method of plasma treatment, which helps to avoid impurities and to preserve the properties of the MWCNTs to be incorporated in the cotton fibers.

\section{Conflict of Interests}

The authors declare that there is no conflict of interests regarding the publication of this paper.

\section{Acknowledgments}

This study was supported by the Promotion of Nano-Biotechnology Research to Support Aging, Welfare Society from Ministry of Education, Culture, Sports, Science and Technology, Japan. The authors used the TEM and TG/DTA at Research Institute of Green Science \& Technology, Shizuoka University.

\section{References}

[1] L. B. Hu, M. Pasta, F. La Mantia et al., "Stretchable, porous, and conductive energy textiles," Nano Letters, vol. 10, no. 2, pp. 708714, 2010.

[2] P. Lukowicz, T. Kirstein, and G. Tröster, "Wearable systems for health care applications," Methods of Information in Medicine, vol. 43, no. 3, pp. 232-238, 2004.

[3] S. Park and S. Jayaraman, "Smart textiles: wearable electronic systems," MRS Bulletin, vol. 28, no. 8, pp. 585-591, 2003.

[4] J.-W. Han, B. Kim, J. Li, and M. Meyyappan, "A carbon nanotube based ammonia sensor on cotton textile," Applied Physics Letters, vol. 102, no. 19, Article ID 193104, 4 pages, 2013.

[5] K. Wang, P. Zhao, X. Zhou, H. Wu, and Z. Wei, "Flexible supercapacitors based on cloth-supported electrodes of conducting polymer nanowire array/SWCNT composites," Journal of Materials Chemistry, vol. 21, no. 41, pp. 16373-16378, 2011.

[6] C. Yuan, L. Hou, D. Li, L. Shen, F. Zhang, and X. Zhang, "Synthesis of flexible and porous cobalt hydroxide/conductive cotton textile sheet and its application in electrochemical capacitors," Electrochimica Acta, vol. 56, no. 19, pp. 6683-6687, 2011.

[7] B. S. Shim, W. Chen, C. Doty, C. Xu, and N. A. Kotov, "Smart electronic yarns and wearable fabrics for human biomonitoring made by carbon nanotube coating with polyelectrolytes," Nano Letters, vol. 8, no. 12, pp. 4151-4157, 2008.

[8] D. Negru, C. T. Buda, and D. Avram, "Electrical conductivity of woven fabrics coated with carbon black particles," Fibres \& Textiles in Eastern Europe, vol. 20, no. 1(90), pp. 53-56, 2012.

[9] D. Janas and K. K. Koziol, "A review of production methods of carbon nanotube and graphene thin films for electrothermal applications," Nanoscale, vol. 6, no. 6, pp. 3037-3045, 2014.

[10] A. Abbas, Y. Zhao, J. Zhou, X. Wang, and T. Lin, "Improving thermal conductivity of cotton fabrics using composite coatings containing graphene, multiwall carbon nanotube or boron nitride fine particles," Fibers and Polymers, vol. 14, no. 10, pp. 1641-1649, 2013.
[11] Y. Liu, X. Wang, K. Qi, and J. H. Xin, "Functionalization of cotton with carbon nanotubes," Journal of Materials Chemistry, vol. 18, no. 29, pp. 3454-3460, 2008.

[12] E. R. Post, M. Orth, R. R. Russo, and N. Gershenfeld, "Ebroidery: design and fabrication of textile-based computing," IBM Systems Journal, vol. 39, no. 3-4, pp. 840-860, 2000.

[13] R. F. Service, “Electronic textiles charge ahead," Science, vol. 301, no. 5635, pp. 909-911, 2003.

[14] L. Zheng, X. Zhang, Q. Li et al., "Carbon-nanotube cotton for large-scale fibers," Advanced Materials, vol. 19, no. 18, pp. 25672570, 2007.

[15] D. S. Hecht, L. Hu, and G. Grüner, "Electronic properties of carbon nanotube/fabric composites," Current Applied Physics, vol. 7, no. 1, pp. 60-63, 2007.

[16] A. G. Gonçalves, B. Jarrais, C. Pereira, J. Morgado, C. Freire, and M. F. R. Pereira, "Functionalization of textiles with multi-walled carbon nanotubes by a novel dyeing-like process," Journal of Materials Science, vol. 47, no. 13, pp. 5263-5275, 2012.

[17] P. Kim, L. Shi, A. Majumdar, and P. L. McEuen, "Thermal transport measurements of individual multiwalled nanotubes," Physical Review Letters, vol. 87, no. 21, Article ID 215502, 4 pages, 2001.

[18] A. M. Marconnet, M. A. Panzer, and K. E. Goodson, "Thermal conduction phenomena in carbon nanotubes and related nanostructured materials," Reviews of Modern Physics, vol. 85, no. 3, pp. 1295-1326, 2013.

[19] D. Janas and K. K. Koziol, "Rapid electrothermal response of high-temperature carbon nanotube film heaters," Carbon, vol. 59, pp. 457-463, 2013.

[20] J. Kang, H. Kim, K. S. Kim et al., "High-performance graphenebased transparent flexible heaters," Nano Letters, vol. 11, no. 12, pp. 5154-5158, 2011.

[21] K. Chu, D. Kim, Y. Sohn, S. Lee, C. Moon, and S. Park, "Electrical and thermal properties of carbon-nanotube composite for flexible electric heating-unit applications," IEEE Electron Device Letters, vol. 34, no. 5, pp. 668-670, 2013.

[22] H. C. Neitzert, L. Vertuccio, and A. Sorrentino, "Epoxy/ MWCNT composite as temperature sensor and Electrical heating element," IEEE Transactions on Nanotechnology, vol. 10, no. 4, pp. 688-693, 2011.

[23] M. J. Rahman and T. Mieno, "Water-dispersible multiwalled carbon nanotubes obtained from citric-acid-assisted oxygen plasma functionalization," Journal of Nanomaterials, vol. 2014, Article ID 508192, 9 pages, 2014.

[24] G. Yu, L. Hu, M. Vosgueritchian et al., "Solution-processed graphene $/ \mathrm{MnO}_{2}$ nanostructured textiles for high-performance electrochemical capacitors," Nano Letters, vol. 11, no. 7, pp. 2905-2911, 2011.

[25] S. Hu, R. Rajamani, and X. Yu, "Flexible solid-state paper based carbon nanotube supercapacitor," Applied Physics Letters, vol. 100, no. 10, Article ID 104103, 4 pages, 2012.

[26] Ö. Ceylan, L. van Landuyt, H. Rahier, and K. de Clerck, "The effect of water immersion on the thermal degradation of cotton fibers," Cellulose, vol. 20, no. 4, pp. 1603-1612, 2013.

[27] I. M. De Rosa, J. M. Kenny, D. Puglia, C. Santulli, and F. Sarasini, "Morphological, thermal and mechanical characterization of okra (Abelmoschus esculentus) fibres as potential reinforcement in polymer composites," Composites Science and Technology, vol. 70, no. 1, pp. 116-122, 2010. 
[28] T. Ragab and C. Basaran, "Joule heating in single-walled carbon nanotubes," Journal of Applied Physics, vol. 106, no. 6, Article ID 063705, 5 pages, 2009.

[29] T. Markevicius, N. Olsson, R. Furferi, and H. Meyer, "Flexible mild heaters in structural conservation of paintings: state of the art and conceptual design of a new carbon nanotubes-based heater," Journal of Applied Sciences, vol. 12, no. 3, pp. 211-220, 2012. 

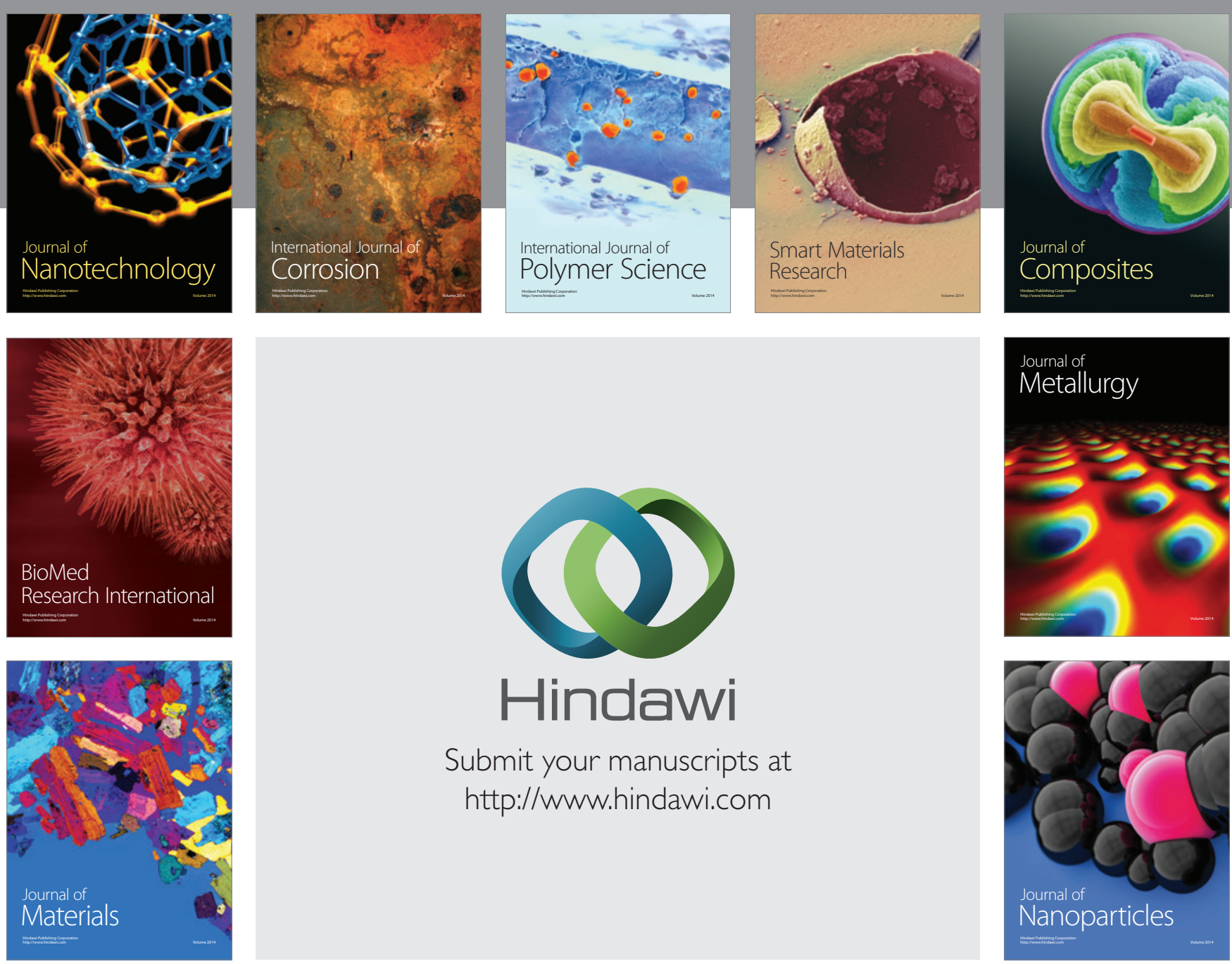

Submit your manuscripts at http://www.hindawi.com
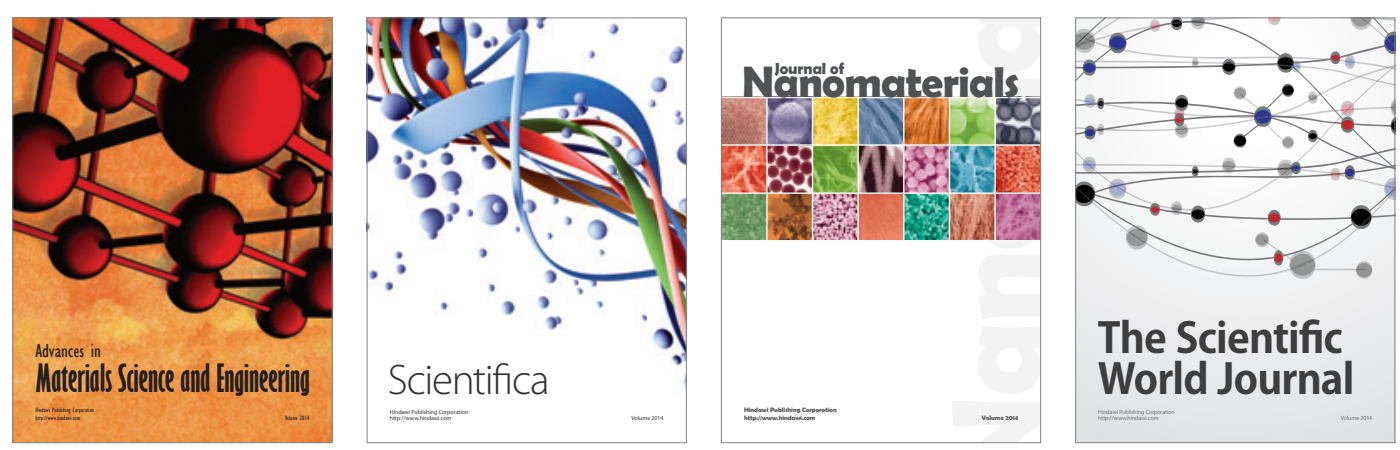

\section{The Scientific World Journal}
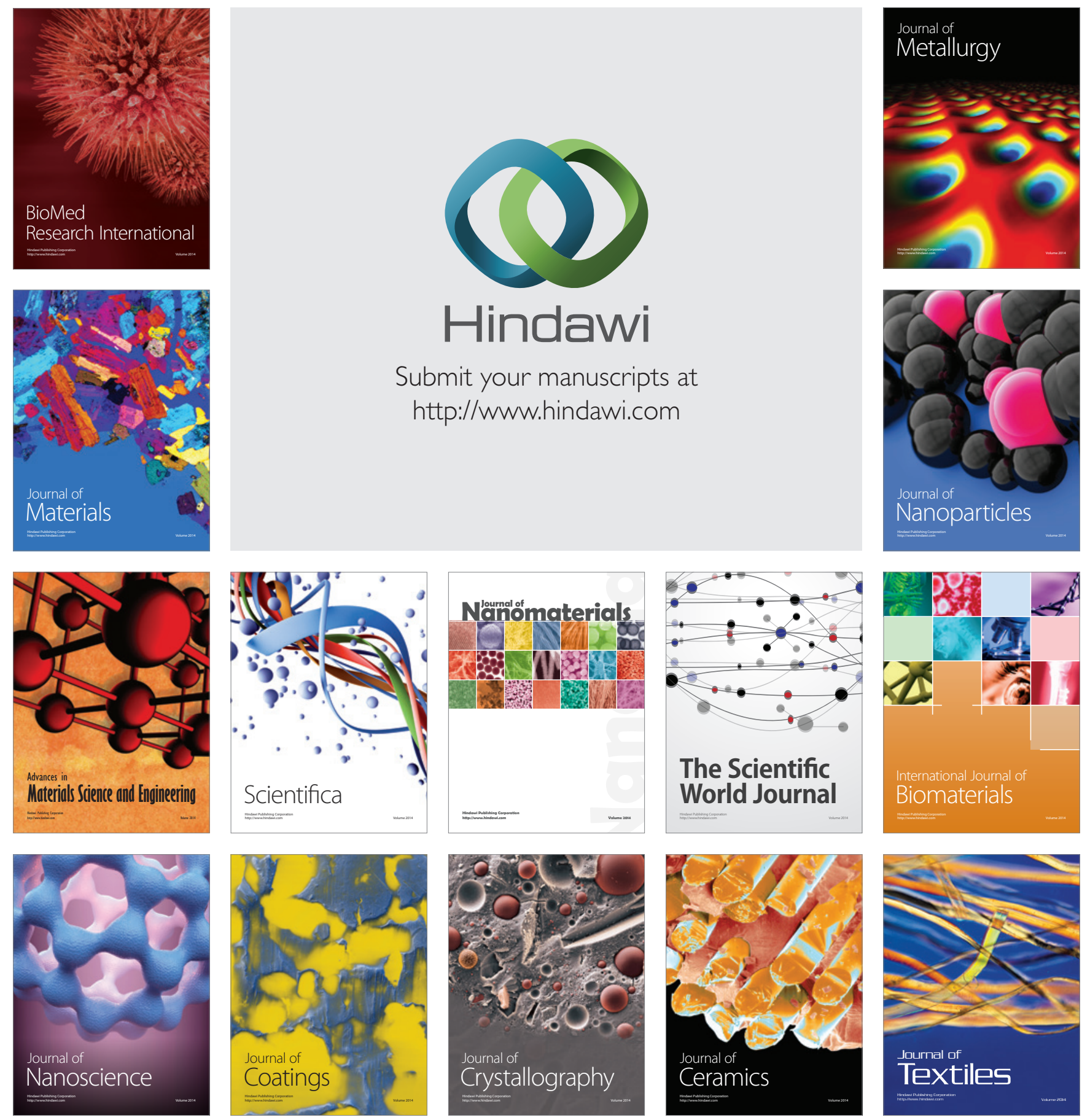